\title{
Molecular analysis of AbOmpA type-1 as immunogenic target for therapeutic interventions against MDR Acinetobacter baumannii infection
}

\author{
Badmasti $\mathbf{F}^{1}$, Siadat $\mathrm{SD}^{1^{*}}$, Bouzari $\mathrm{S}^{2}$, Nasiri $\mathbf{O}^{1}$, Nemati $\mathbf{H}^{1}$, Shahcheraghi $\mathbf{F}^{1^{*}}$ \\ ${ }^{1}$ Department of Bactriology, Pasteur Institute of Iran, Tehran, Iran. \\ ${ }^{2}$ Department of Molecular Biology, Pasteur Institute of Iran, Tehran, Iran.
}

\begin{abstract}
Introduction: Acinetobacter baumannii is associated with hospital-acquired infections. Outer membrane protein A of A.baumannii (AbOmpA) is a well-characterized virulence factor which has important roles in pathogenesis of this bacterium. Methods: Based on our PCR-sequencing of ompA gene in the clinical isolates, AbOmpA protein can be categorized into two types, named here type-1 and type- 2 . We are performed in silico analyses on beta-barrel domain of AbOmpA such as sequence alignments, prediction of 3D modeling and immunoinformatics. Results: High prevalence of AbOmpA type-1 were detected both in 21 multidrug-resistant (MDR) A. baumannii isolates collected from clinical settings (64\% of total sequences) and in silico sequences extracted from Uniprot database (49.7\% of total sequences). Multiple sequence alignments and phylogenic tree revealed AbOmpA sequences in comparison with OmpA of Enterobacteriaceae family were more heterogenic, especially at extracellular loops amino acid positions and were evolutionary far from this family. Characterization of in silico 3D molecular model of beta-barrel domain of AbOmpA type-1 showed this domain had four large extracellular loops which resemble to beta-barrel domain of Klebsiella pneumonia OmpA (KpOmpA). Immunoinformatics analyses showed the four extracellular loops had high scores as B and T cell antigenic epitopes especially in loop-1 and 3. Geometry analyses revealed extracellular loops effectively protrude to outer space of the cell. Conclusion: Beta-barrel domain of AbOmpA type-1 has all the characteristics of a promising vaccine and could be considered as an excellent target for a vaccine against MDR A. baumannii infection.
\end{abstract}

KEYWORDS: beta-barrel domain of AbOmpA, Alignment, phylogenic tree, in silico 3D molecular model, epitope prediction.

\section{INTRODUCTION}

Acinetobacter baumannii is a Gram-negative bacterium associated with hospital-acquired infections. It has become an increasingly important human pathogen because of the increase in the number of infections caused by this organism and the emergence of multidrug-resistant (MDR) strains [1]. Much is known about the processes involved in antimicrobial resistance of $A$.baumannii, but the pathogenicity and virulence factors of this organism are beginning to be highlighted in recent years.

*Corresponding Author: Seyed Davar Siadat, Ph.D; Department of Mycobacteriology and Pulmonary Research, Pasteur Institute of Iran, Tehran, Iran.

Email: d.siadat@gmail.com

Tel/Fax: (+98) 2166969291

*Co- Corresponding Author: Fereshteh Shahcheraghi, Ph.D; Department

of Bactriology, Pasteur Institute of Iran, Tehran, Iran.

Email: shahcheraghifereshteh@yahoo.com

Tel/Fax: (+98) 2166405535
OmpA (previously Omp38) of A. baumannii (AbOmpA) is one the most well-characterized important virulence factors of this bacterium which has been reported to be associated with adherence and invasion of eukaryotic cell, biofilm formation, apoptosis, immune stimulation, outer membrane vesicle biogenesis, iron metabolism and serum resistance [2]. The adherence and invasion roles of AbOmpA may contribute to the dissemination of $A$. baumannii during the infection. The bacterial loads in blood of mice models have been reported to be significantly decreased with isogenic ompA mutant in comparison to the wild-type strain [3]. The apoptosis events have been shown in human HEp-2 cells and dendritic cells as the results of localization and presumed activity in the mitochondria or DNase activity in the nucleus [4-5]. Moreover at sub-lethal concentrations, AbOmpA is known to activate dendritic cells through TLR2, and both MAPK and NF- $\mathrm{BB}$ pathways which results in stimulation and differentiation of CD4+ T cells toward a Th1 polarizing phenotype through the activation of dendritic cells [6]. 
The molecular structure of beta-barrel domain of AbOmpA has not yet been characterized experimentally. However, OmpA of Escherichia coli (EcOmpA) is a well-studied example of this protein. Both experimental and hypothetical models have shown that EcOmpA protein could be divided into four parts in this order: a signal peptide sequence, an $\mathrm{N}$-terminal beta-barrel domain with 8 beta stranded structure with four extracellular loops, a hinge region and finally a C-terminal OmpA-like domain which has a high proportion of alpha-helix interacting with the peptidoglycan layers. EcOmpA roles include functioning as an adhesion and invasin, participating in biofilm formation, acting as an immune target and serving as a receptor for several bacteriophages[7]. Many of these properties are due to four long loops of its beta-barrel domain that emanate from the protein to the outside of the cell [8]. Moreover, the solution state NMR structure of beta-barrel domain of Klebsiella pneumonia OmpA (KpOmpA) has shown this domain to have significantly larger extracellular loops in comparison with its $E$. coli homologue [9].

Ideally, a promising vaccine candidate protein should be conserved and have important roles in pathogenesis of the microorganism with high prevalence among all disease-causing strains of that pathogenic species. Moreover, it should be exposed to the extracellular spaces so that could be effectively presented to the immune system. In addition, it should have one or more epitopes which could elicit a protective immune response in the relevant animal models [10]. In our previous work, we detected ompA gene in all clinical isolates and its expression in each isolate was confirmed by Western blotting [11]. Our goal in this project was to asses AbOmpA as a vaccine candidate against MDR A. baumannii infection.

\section{MATERIALS and METHODS}

\section{PCR, sequencing and typing of AbOmpA}

Twenty one MDR clinical isolates of $A$. baumannii were collected from three hospitals which had been recovered from blood, throat and urine samples. The disk diffusion method was used to determine the susceptibility of isolates to imipenem, ciprofloxacin, and gentamicin (MAST Laboratories Ltd., Merseyside, UK). Clinical isolates that were absolutely resistant to these antibiotics were considered as MDR A. baumannii. Genomic DNA of every isolate was extracted by Invitek DNA extraction kit (STRATEC Biomedical AG, Birkenfeld, Germany). Polymerase chain reaction (PCR) assays were performed by PCR Master Mix Red (Ampliqon, Herlev, Denmark). The forward primer (ompF) was 5'ATGAAATTGAGTCGTATTGC-3' and the reverse primer (ompR) was 5'-TTATTGAGCTGCTGCAGGAG-3'. PCR program was done as follows: Initial denaturation $\left(95^{\circ} \mathrm{C}\right) 10$ min, denaturation step $\left(95^{\circ} \mathrm{C}\right) 30 \mathrm{~s}$, annealing step $\left(58^{\circ} \mathrm{C}\right) 30 \mathrm{~s}$, extension step $\left(72^{\circ} \mathrm{C}\right) 1 \mathrm{~min}$. The PCR cycle was repeated 30 times in thermocycler (Mastercycler EP Gradient, Eppendorf). DNA pieces with $\sim 1050$ bp molecular weight were extracted from agarose gel by GeneJETGel Extraction Kit (Fermentas, Burlington, ON, Canada) and were sequenced by ABI 3730XLs automatic sequencer at Macrogen Inc. (Seoul, Korea). AbOmpA nucleotide sequences of 21 MDR clinical isolates were translated to amino acid sequences, based on bacterial codon usage. Sequences were compared with GenBank database and then were classified based on sequence diversity. Multiple sequence alignments and phylogenic tree
All full-length OmpA amino acid sequences were collected from Uniprot database; a freely accessible resource for protein sequences and functional information [12]. Data were saved in FASTA format. The redundancies of sequences were excluded. Multiple sequence alignments were done by ClustalX [13].The phylogenic tree was depicted by MEGA v. 6.0 [14]. Phylogram was constructed based on Neighbor-Joining method. The amino acid substitution model was $\mathrm{p}$-distance. The reliability of tree was tested by bootstrap method (500 units). The gamma actin-1 (human protein) was used as a control gene for checking the method's correctness.

In silico molecular 3D modeling of beta-barrel domain

AbOmpA of A. baumannii strain AB-64 was selected as a candidate for characterization of 3D modeling (NCBI protein accession number: AKF11891). Domain prediction revealed AbOmpA had two independent domains, named beta-barrel domain at $\mathrm{N}$-terminal and OmpA-like domain at C-terminal of this protein. The C-terminal OmpA-like domain had been previously characterized under accession numbers $4 \mathrm{G} 4 \mathrm{~V}$, 4G4W and 4G4X in Protein Data Bank. Therefore, this study focused on N-terminal beta-barrel domain of AbOmpA. The 3D structure modeling was performed on beta-barrel domain of AbOmpA (from Gly23 to Lys194). Prediction of 3D modeling was done by five web servers, namely LOMETS, I-TASSER, Psipred, Phyre2, and 3D-JIGSAW. All output models were qualitatively estimated by QMEAN (a composite scoring function which is able to derive both global (i.e. for the entire structure) and local (i.e. per residue) error estimates on the basis of one single model [15]), PROSESS (a web server designed to evaluate and validate protein structure solved by either X-ray crystallography or NMR spectroscopy [16]) and NQ-Flipper (a web server that recognizes unfavorable rotamers of Asn and Gln residues in protein structures [17]). Furthermore, the Ramachandran plots were also depicted for each model by Rampage [18]. The Ramachandran plot displays the main chain conformation angles (Phi and Psi) of the polypeptide chain of a protein molecule. One predicted model with the highest score was selected as the structural model of beta-barrel domain of AbOmpA and then energy minimization refinements were performed at Modrefiner online tool (a high-resolution protein structure refinement web server[19]). The refined model was validated by PorSA web server (an interactive web service for the recognition of errors in three-dimensional structures of proteins[20]). Geometric analysis of the 3D model was done in 3D-SURFER 2.0 (a web-based tool for real-time protein surface comparison and analysis[21]).The URL of the servers which were used in this study are listed in Table 1.

\section{Linear and conformational epitopes prediction}

Linear B cell epitopes of the beta-barrel domain were predicted by BepiPred [22]. Conformational B cell epitopes were characterized by five independent prediction web servers as BEpro (a hidden Markov model based server for discontinuous B-cell epitope prediction [22]), EPCES (prediction tool of antigenic epitopes on protein surfaces by consensus scoring [23]), EPSVR (an antigenic epitopes prediction tool with support vector regression [24]), Discotope (a server that predicts discontinuous $\mathrm{B}$ cell epitopes from protein 3D structures by calculation of surface accessibility and a novel epitope propensity amino acid score [25]) and Ellipro (a structure-based tool for the prediction of antibody epitopes [26]). Prediction of MHC-I and MHC-II binding sites were done by IEDB analysis resource[27-28].The URL of the servers which were used in this study are listed in Table 1. 
Table 1. All web servers which were used in this study

\begin{tabular}{|c|c|c|c|}
\hline Web server & URL & Characteristics & Reference \\
\hline GenBank & http://www.ncbi.nlm.nih.gov/genbank/ & Genetic sequence database & [35] \\
\hline Uuniprot & http://www.uniprot.org/ & Resource of protein sequences & [12] \\
\hline Conserved Domain & http://www.ncbi.nlm.nih.gov/Structure/cdd/wrpsb.cgi & Conserved domain database & [36] \\
\hline Protein Data Bank & http://www.rcsb.org/pdb/home/home.do & A resource of 3D structure of proteins & [37] \\
\hline LOMETS & http://zhanglab.ccmb.med.umich.edu/LOMETS/ & Local Meta-Threading Servers & [38] \\
\hline I-TASSER & http://zhanglab.ccmb.med.umich.edu/I-TASSER/ & Tertiary structure predictor based on multiple threading alignments & [39] \\
\hline Psipred & http://bioinf.cs.ucl.ac.uk/psipred/ & Modeling based on fold recognition & [40] \\
\hline Phyre2 & http://www.sbg.bio.ic.ac.uk/phyre2/ & Tertiary structure predictor based on homology modeling & [41] \\
\hline 3D-JIGSAW & http://bmm.cancerresearchuk.org/ 3djigsaw/ & Tertiary structure predictor based on homology modeling & [42] \\
\hline QMEAN & http://swissmodel.expasy.org/qmean/cgi/index.cgi?page & A comprehensive scoring function for model quality assessment & [15] \\
\hline PROSESS & http://www.prosess.ca/ & A web server designed to evaluate and validate protein structures & [16] \\
\hline NQ-Flipper & https://flipper.services.came.sbg.ac.at/ & Predictor of unfavorable rotamers of Asn and Gln residues in protein structures & [17] \\
\hline Rampage & http://mordred.bioc.cam.ac.uk/ rapper/rampage.php & Ramachandran Plot generator & [18] \\
\hline Modrefiner & http://zhanglab.ccmb.med.umich.edu/ModRefiner/ & high-resolution protein structure refinement web server & [19] \\
\hline DALILITE & http://ekhidna.biocenter.helsinki.fi/dali_server & Structural alignment tool & [43] \\
\hline 3D-SURFER & http://kiharalab.org/3d-surfer/submit.php & Protein geometry analyzer & [21] \\
\hline BepiPred & http://tools.immuneepitope.org/bcell/ & Linear B cell epitopes predictor & [44] \\
\hline BEpro & http://pepito.proteomics.ics.uci.edu/ & predictor of conformationl B-cell epitopes & [45] \\
\hline EPCES & http://sysbio.unl.edu/EPCES/ & Predictor of conformational antigenic epitopes on protein surfaces & [23] \\
\hline EPSVR & http://sysbio.unl.edu/EPSVR/ & Predictor of conformational antigenic epitopes with support vector regression & [24] \\
\hline Discotope & http://www.cbs.dtu.dk/services/DiscoTope/ & Predictor of conformational antigenic epitopes with calculation of surface accessibility & [25] \\
\hline Ellipro & http://tools.immuneepitope.org/tools/ElliPro/iedb_input & Structure-based tool for the prediction of antibody epitopes & [26] \\
\hline MHC-I & http://tools.immuneepitope.org/mhci/ & Predictor of MHC-I peptide binding sites & [27] \\
\hline MHC-II & http://tools.immuneepitope.org/mhcii/ & Predictor of MHC-II peptide binding sites & [28] \\
\hline
\end{tabular}




\section{RESULTS}

\section{Experimental sequence typing.}

Analysis of 21 AbOmpA DNA sequences following translation to amino acids showed that all AbOmpA could be categorized into two types, named type-1 (64\% of total sequences) and type-2 (33\% of total sequences). Pairwise local alignments revealed that both types had $94 \%$ sequence identity to each other and the variation regions $(6 \%)$ were exactly located on extracellular loops of the beta-barrel domains. The information of 21 MDR clinical isolates and AbOmpA typing are summarized in Table 2. DNA Sequences of type-1 and type-2 were deposited in GenBank database under accession numbers KP271243 and KP271242, respectively.

Table 2. The information of $21 \mathrm{MDR}$ clinical isolates and typing of AbOmpA based on sequence diversity. Analysis of 21 AbOmpA genes showed all sequences could be categorized in two types named type-1 (14 of 21 sequences) and type- 2 ( 7 of 21 sequences). DNA Sequences of type- 1 and type- 2 were deposited in GenBank database under accession numbers KP271243 and KP271242, respectively.

\begin{tabular}{|c|c|c|c|}
\hline Isolate & Hospital & Isolation source & AbOmpA Туре \\
\hline 1 & $\mathrm{~B}$ & Blood & 2 \\
\hline 2 & $\mathrm{C}$ & Throat & 1 \\
\hline 3 & $\mathrm{C}$ & Urine & 2 \\
\hline 4 & $\mathrm{C}$ & Blood & 1 \\
\hline 5 & $\mathrm{C}$ & Blood & 2 \\
\hline 6 & A & Blood & 2 \\
\hline 7 & $\mathrm{~B}$ & Throat & 1 \\
\hline 8 & $\mathrm{C}$ & Blood & 2 \\
\hline 9 & $\mathrm{C}$ & Sputum & 2 \\
\hline 10 & $\mathrm{C}$ & Blood & 1 \\
\hline 11 & $\mathrm{C}$ & Blood & 1 \\
\hline 12 & $\mathrm{C}$ & Throat & 1 \\
\hline 13 & $\mathrm{C}$ & Throat & 1 \\
\hline 14 & $\mathrm{C}$ & Throat & 1 \\
\hline 15 & $\mathrm{C}$ & Blood & 1 \\
\hline 16 & $\mathrm{C}$ & Blood & 1 \\
\hline 17 & $\mathrm{C}$ & Wound & 1 \\
\hline 18 & $\mathrm{C}$ & Blood & 1 \\
\hline 19 & $\mathrm{C}$ & Blood & 1 \\
\hline 20 & $\mathrm{C}$ & Throat & 2 \\
\hline 21 & $\mathrm{C}$ & Blood & 1 \\
\hline
\end{tabular}

\section{Alignment of in silico sequences and phylogenic tree.}

Fifty four full length sequences of AbOmpA protein (nonredundant sequences) were extracted from Uniprot database. The signal peptide and C-terminal, OmpA like domain of AbOmpA sequences were removed and then redundant sequences were excluded. Multiple sequence alignment of the 37 non-redundant beta-barrel domains revealed clear diversity regions, corresponding to four segments, as shown in Fig. 1.
The phylogram includes non-redundant sequences of OmpA (redundancy sequence cut-off $\geq 99 \%$ ). This tree which represents AbOmpA has more heterogeneity and is evolutionarily far from Enterobacteriaceae family (Fig. 2).

3D Modeling, evaluation and validation.

Ten models were collected from LOMETS web server. The quality values of the models were computed by QMEAN, PROSESS and NQ-Flipper. The Summarized information of ten models which had been evaluated by QMEAN, PROSSES, NQFlipper and Ramachandran online tools are deposited in Table 3. The LOMETS-3 model which had the best score was considered as the beta-barrel model of AbOmpA protein and was refined by Modrefiner tool. This model represents 8 transmembrane beta strands, 4 extracellular large loops (L1, L2, L3, and L4) and short periplasmic turns (Fig.3A). The L1, L2, L3 and L4 include 21, 19, 15 and 15 residues, respectively. The Ramachandran plot of the refined model estimated the number of residues in the favored region to be $168(98.8 \%)$, the number of residues in allowed region to be $2(1.2 \%)$ and the number of residues in the outlier region to be $0(0 \%)$, as shown in Fig. 3B. The refined model was validated by PorSA web server. The Zscore of the model was in acceptable range $(-2.66)$ as represented in Fig. 3C.

\section{Geometry characterization.}

Protrusion analysis of the beta-barrel domain showed three major exposed volumes as first largest protrusion (red volume, surface area $=1933.89$ and volume $=5987.911$ ) including Gly43, Gly44, Lys45, Asp46, Gly47, Asn48, Thr50, Asn51, Ser52, Glu54, Lys55, Asp135, Arg139, Thr141, Arg142, Thr144 and Glu146 residues, located in L1 and L3, second largest protrusion (green volume, surface area $=854.060$ and volume $=1710.544$ ) including Asp87, Gly88, Ala89, Ser90, Ala91, Tyr95, Lys96, Gln97, Lys98 and Ile100 residues located in L2 and third largest protrusion (blue volume, surface area = 572.676 and volume $=794.127$ ) including Arg172, Thy175, Asn176 and Glu180 residues, located in L4 (Fig 3D). Protrusion analysis confirmed that the extracellular loops had excellent characteristics which could be effectively presented to the immune system.

\section{Epitopes prediction of beta-barrel domain} Linear and conformational $B$ cell epitopes prediction.

Analysis of linear B cell epitopes revealed that the regions of the extracellular loops had high scores as B cell epitopes (Fig. 4). The summarized prediction of the conformational epitopes by five independent online tools showed that four regions approximately corresponding to the four extracellular loops (Table 4).

\section{MHC-I and MHC-II binding sites prediction.}

In this section, MHC- binding sites of inbred mice alleles which are commonly used as A. baumannii infection models (such as $\mathrm{BALB} / \mathrm{c}$ and $\mathrm{C} 57 \mathrm{BL} / 6)$ were predicted. Analysis of the betabarrel sequence showed that amino acids which were located on extracellular loops had great potential as MHC-binding sites where L1 and L3 had especially more MHC-binding sites. MHC-I and MHC-II binding sites of the beta-barrel domain are represented in Fig 5A and 5B, respectively. 


\begin{tabular}{|c|c|c|c|c|c|c|c|c|c|c|}
\hline & 10 & & 40 & & 100 & & 140 & 150 & & \\
\hline & OVTVTPLLLGYTF & & LLFVAALOIELTPWLOFEAEYNOVK & - ASAQAE & YVTSDLITKNYOSK I I PYVLLGAOH & & GTLONAQVGAFWR̈ & & & AOLNV \\
\hline MAOAOI INEBS:-172 & OVTVTPLLLOYTF & DSOHNNGOKDONLTNAPELO & LIFUAALOIELTPWLOFEAEYNOV & OVDO. ASAOAEYKOKOINON & YVTSOLITKNYOSKIKPYVLLOAGH & YOFDOVNR. & GTLONAGVGAFWR & RLNDALSL & YNADEEFWNY & AOLNV \\
\hline MAOAOOSWOY:-172 & OVTVTPLLLOYTF & DSQHNNOQKDONLTNOPELO & LLFVOALOIELTPWLOFEAEYNOV & OVDO. ASAGAEYKOKQINON & GTSOLITKNYOSK & YOFDOVNR. & OTLONAGVGAFWR & RLNDALS & NADEEFWNYY & AOLLVVL \\
\hline THAOAOO9G2L4/1-172 & OVTVTPLLLOYTF & DSQHNNOOKDONLTNSPEL & DLFVOAALO IELTPWLOFEAEYNOV & OVDO. ASAQAEYKQKQINON & YVTSOLITKNYOSKI & YOFDOVNR. & OTLONAOVGAFWR & RLNDALSLR & NADEEFWNY & \\
\hline HLLMMIEA//1-172 & OVTVTPLLLOYTF & OSQHNHOOKDONLTNOPELO & DLFVOAALOIELTPWLOFEAEYNOV & OVDO. ASAQAEYKOKQINON & YVTSOLITKNYOSKI & YOFDOUSR. & - TLONAOVOAFWR & RLNDALSLRTE & HADEEFWNY & AOLNVVL \\
\hline 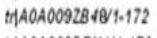 & OVTVTPLLLOYTF & DSOHNNOOKDONLTNSPELQL & PLFVOAALOIELTPWLOF EAEYHOV & OVDO. ASAOAEYKOKQINON & YVTSOLITKNYOSKI & YOFDOUNS. & OTLONAQVOAFWR & RLLDALSLRTE & NADEEFWNYTA & AOLLVVL \\
\hline MAOAO298PNY/1.172 & TPLLLOYTF & & ULFVOALO IEL TOWLOF EAEYNOV & OVDO. ASAGAEYKOKQINON & YVTSOLITKNYOSK & DOVNR. & GTLONAGVGAFWR & RLNOALSL & & \\
\hline MAOAOOPFF9y $1-172$ & OVTVTPLLLOYTF & DSOHNHOG KDGNLTNAPELQI & PLFVGAALOIELTPWLGF EAEYNOV & OVDO . ASAGAEYKOKOINGN & YVTSOLITKAYOSKI & YOFDOVNR. & GTLGNAGVGAFWR & RLNDALSLRTE & IADEEFWHYTAS & AOLLVVL \\
\hline HAOAO17CFCT/1-172 & OVTVTPLLLOYTF & DSQHANOQKDONLTNSPELQL & PLFVGALLOIELTPWLGFEAEYNQV & OVDO. . ASAGAEYKOKQINGN & YVTSDLITKNYOSKI & YYFDOUNR. & GTLONAGVGAFWR & RLNDALSLRTE & NADEEFWNYTAL & AOL LIVVL \\
\hline THAOAOOSFEWI/1-172 & & & PLFVOAALOIELTPWLOF EAEYNOV & OVDO. ASAOAEYKOKQINON & YVTSOLITKNYOSKI & & OTLONAGVOAFWR & RLNDALSLRTE & & \\
\hline HAOAO1359001.172 & OVTVTPLLLOYTF & DSaHN⿴囗 & PLIVOAALOIELTPWLOFEAEYNOV & OVDO. AAAQAEYKOKOINON & YVTSOLITKNYOSK & Yor & GTLONAQVOAFWR & RLNDALSL & & \\
\hline thAOAOOSR9T81-172 & OVTVTPLLLOYTF & OSOHNNOOKDONLTNOPELOO & PLFVOAALOIELTPWLOFEAEYNOV & OVDO. BVAOAEYKOKOINON & YVTSOLITKNYOSKI & YOFDOVNR. & GTLONAGVOAFWR & RLLNDALSLRTE & TAL & AOL LVVL \\
\hline HAOAOOSWOWO $: 472$ & OVTVTPLLLGMTF & DSOHANQOKDONLTNSPELQL & DLFVOAALOVELT TPWLGF EAEYNOV & OVNO. ASAQAEYKOKQINON & YATSOLITKNYDSKFKPYVLLQAGHT & YOFDOVNR. & G TLONAQIGAFYR & RINDALSLRTE & TYNF DEEFWNYTAL & AOL LVVL \\
\hline THAOAOHONOY/1.172 & OVTVTPLLLGYTF & & PLFVGAALOVELTPWLOF EAEYHOV & DVNO . ASAGAEYKOKQIHON & YATSOLITKHYOSKFE PYVLLOAGHY & & GTLGNaqigafye & RINDALSLRTE & & \\
\hline THAOAOOSEJUA61-172 & OVTVTPLMLOYTW & DTEHMNOGNDOEL TSOPELOO & PLFVGAAIOVELTPWLOFEAEYSOV & OVDO $\cdots$ AAPGAEYKOONIAON & YAT SOVF TQNYOSKI & YEF DOVNR. & OTLONAGIGAFWH & HI NDALALRTE & & AOL HV \\
\hline$M F 5+Y 771:-169$ & OVTVTPLLLOYTF & DTQHNNOGKDOELTNOPELOQ & DLFVGAALOIELTPWLOFEAEYNOV & OVDO. . LSAGAEYKOKQI INON & YVTSOLITKNYDSKI & . LSYHNDE & OTLONAGVGAFWR & RLNDALSLRTE & FWN & AOL HVVL \\
\hline QROWWE 1469 & OVTVTPLLLOYTF & & PLIVOAALOIELTPWLOF EAEYHOV & DVDO - LAAOA & YVTSOLITKNYOSKI & & OTLONAQVGAFWR & RLNDALSLRTE & & \\
\hline HAOAOOSFRUE1.1969 & OVTVTPLLLOYTF & ОТАН世м & DLFVOAALOIELTPWLOFEAEYNOV & OVDQ . LAAQAEYKOKOINON & YVTSOLITKNYYOSKI & & GTLONAQVOAFWR & RLNDALSLRTE & & 4AOLN! \\
\hline thAOAOOSQQN2/4.69 & OVTVTPLLLGYTF & KDOSLTNOPELOQ & PLFVGAALO IELTPWLOFEAEYNOV & DVO..... INYGEYKEKQINON & YVTSOLITKNYOSK & - LAYHOGE & GTLONAGVGAFWR & RLNDALSLRTE & & AOLNV \\
\hline thAOAOOOG ZLU/1:169 & GVTVTPLLLGYTF & DSQHNI & PLFVGAALOIELTPWLOFEAEYNOV & . PNYGEYKOKOINON & YVTSDLITKNYOSKI & YEFDOA.R. & G Tllghagvgafyr & RLNDALSLRTE & & AQLLV \\
\hline & & & PLFVOAALOIELTPWLOFEAEYNOV & pro.....enros & YVTSOLITKNYOSKIKPYVLLOAOHI & & GTLONAGIgaFWR & RLLNALLSLRTE & & \\
\hline MAOAO10K234/1-171 & OVTVTPLLLOYTF & SLTNQPELOR & PLFVOALLOIELTPWLOFEAEYMOV & DVNOI I AQAPNAEYKOKOINON & YVTSOLITKNYYOSKFEPYVLLOAOHI & YEIPO. & GTLONAOIOAFYR & RINDALSLRTE & DFWNY & AOLM \\
\hline MAOAOTXWSY 1.971 & OVTVTPLLLOYTW & DSQHI & PLFVOAALO IELTPWLOFEAEYHOV & OUNOIAOAPNAEYKOKOINON & YVTSOLITKHYDSKFEPYVLLOAOHI & & OTLONAOIOAFYR & RINDALSLRTE & & AOLN \\
\hline HAOAOTOWN2//19.171 & OVTVTPLL & lose & PLFVOAALOIELTPWLOF EAEYNOV & DVNO I POAPNAEYKOKQINON & YVTSOLITKNYYSKFEPYVLLOAGH & YEIF & GTLONAQIQAFYR & RINDALSLRTE & 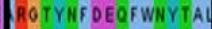 & AOLNV \\
\hline AAOAOINOLOW'-171 & OVTVTPLLLOYTW & XOSLTESPELQd & PLFVOAALO IELTPWLOFEAEYHOV & OUNQIAQAPNAEYKQKQIIHON & YVTSOLITKKYOSKFEPYVLLOAOHI & & otLONAOIOAFYr & RINDALSLRTE & & \\
\hline THAOAOOSKTTB:-171 & OVTITPLMLOYTM & DTQH & LLFVAALOVELTPWLOFEAEYSR & OTS....VAQNEYKOENIAON & YVTSDLFTKNYOSKI & YEFDTOAC & OTLONAGLGAFWR & RINOALSLR & & AQL LN \\
\hline MAOAOOSLHN2/.165 & OVTVTPLIMLOY & DTEHMNRG & LLF VAALOVEITPWLOAEVEYSO & DYRORNI & YVTSOLITKNYOSKI & & GTLANAQGQVFWR & RLNDALSLRTE & Al. & AOLNV \\
\hline AOAOONARE:-165 & & KaOL Tpo & DLFVOALLOVEITPWLOAEVEVSQI & OTS....RN-NOYKORNIAO & YYVTSDLI I KKNYOSKI & resodiro. & GTLANAGGQVFWR & RLNDALSLRTE & & AOL LIV \\
\hline MAOAOO9CMOH-164 & OVTVTPLLVOYTW & . DKLTSHAELQD & PLFVOAALOVELTPWLOFEAEYNOV & OLEO-TOVAOSEYKOKTIAON & YATSDLITKHYOSKFEPYVLLOAOQ & TEFDQ... & DTínagvoafyr & RLNDALSLRTE & KYWRY & AOLLV \\
\hline THAOAOO9FBA $/ / 1-164$ & OVTVTPLLLOYTW & DSEHNN. & PLFVGAOLOVELTPWLOFEAEYNOV & DLOO-TOVOQAEYKOKTIAC & YATSOLITKNYOSKF KPYVLLOAQO & TEF & DTIONaOVGafyr & RLINALLSLR & ir & AOLNI \\
\hline HAOAOIITTME/.164 & OVTVTPLLVOYTW & $\because$ OKLTSHAELOL & DLFVOAALOVELT PWLOF EAEYNOV & DLOQ. TOVAGAEYKOKTVAO & YATSOLITKHYOSKFKPYVLLOAOO & TEFDO. & DTIONaqigafyr & RLNDALSLRTE & & QOLM \\
\hline & & DSEHNN. & LFVGAALOVELTPWLOF EAEYNOV & DLDQ. TQVAC & & & & & & \\
\hline TAAOAOO9GWHA/1:165 & GVTVTPLLLOYTF & DSEHWN. & PLIVOAALOIELTPWLOFEAEYHOV & EYKOKOINGN & YVTSDLITKNYOSKIKPYVLLOAGHI & Yorod & OTLGNAGVAF & RLNDALSLF & & \\
\hline MAOAOOSHE $3 / 1 / 165$ & GVTVTPLLLLYT & TOSPELQ & PLFVOAALOIELTPWLOF EAEYNOV & OVO..... BNYOEYKOKQINON & YVTSDLITKNYOSKIKPYVLLOAGH & $Y D F D D A \cdot R$ & Gillonaguafwr & RLNDALSLR & 201 & AQLN \\
\hline MAOAOOMARQ1-175 & OVTVTPLMLOYT & OTKHNNQ . DKHLTNQPEI & LFVOAALO IELT TPWLOF EAEYHOV & OVDQ. . ATPNAEYKOQQ I INON & YVTSDLITKNYOSKIKPYVLLOAOHI & YKFDDATAAEFGRAGRQLKE & OTLONAGFOAFWR & RLNDALSL & & \\
\hline 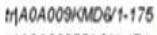 & OVTVTPLMLOYTI & DTKHNNS. & LFVOALLOIELTPWLOF EAEYNOV & DVDA, ATPNAEYKOQQO INON & YVTSOLITKNYOSKIKPYVLLOAOH & & OTLONAGFOAFWR & RLNOALSL & & \\
\hline 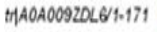 & OVIVIPLLLOYIF & DIEHEN .... NKLINAPELLO & PLFVOAALOVELTPWLOF EAEYNOVK & OVOQ - SIAQAEYKOKQINON & YVISOLLITKHYOSKIKPYVLLOAOHY & & JiLONAQVGaFWR & RLNDALSLI & & AOLLNVLL \\
\hline
\end{tabular}

Fig. 1. Multiple sequence alignments of beta-barrel domain of AbOmpA proteins (according to NCBI protein accession number AKF11891, beta-barrel domain includes Gly23 to Lys194) which have been extracted from Uniprot database. In this figure, there are 37 non-redundant diversity patterns. Alignments exhibited that the sequences have diversity segments corresponding to four extracellular loops as marked by the black rectangles. 


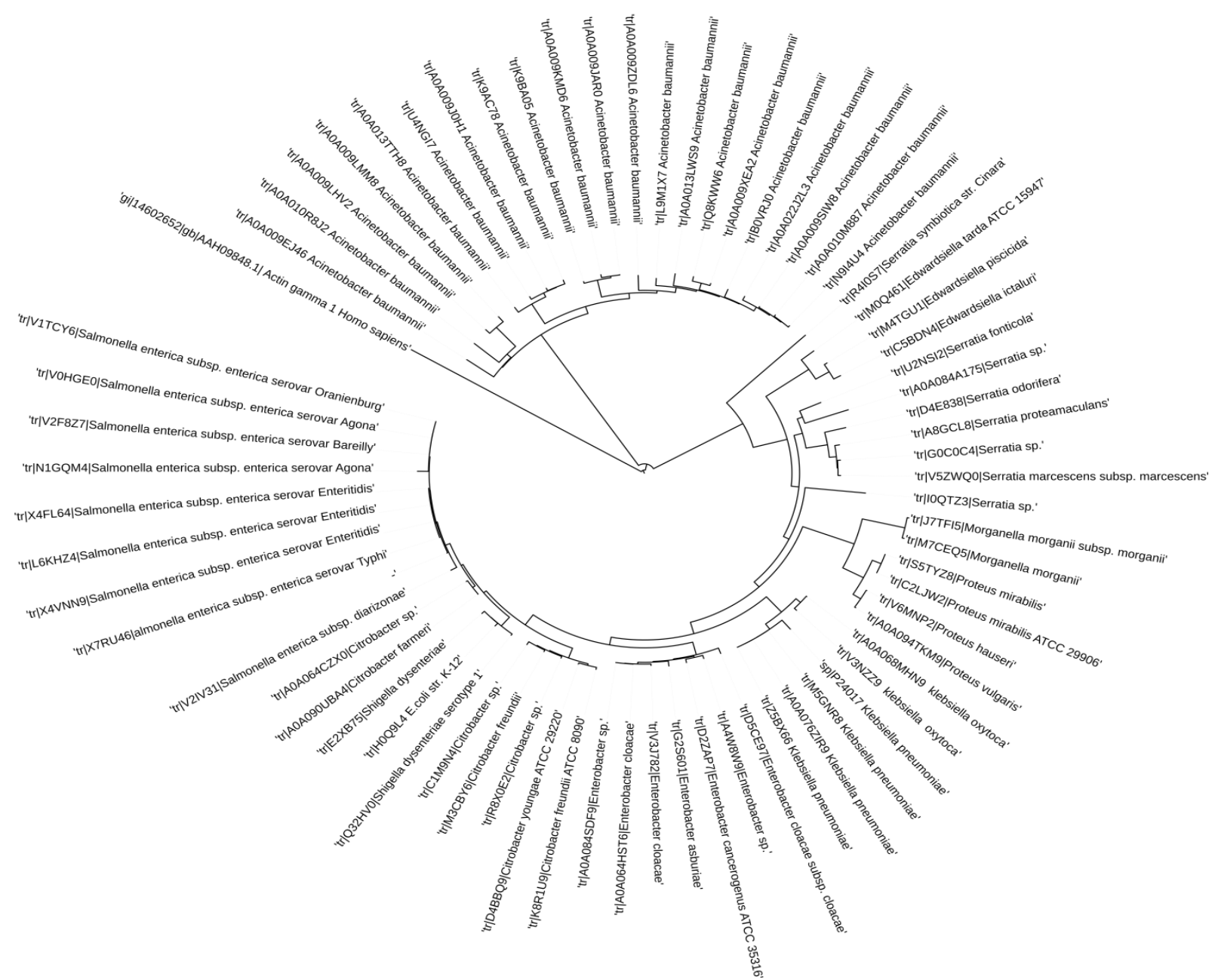

Fig. 2. The circular Neighbor-Joining phylogram of full length OmpA from A.baumannii and Enterobacteriaceae family (redundancy sequence cut-off $\geq 99 \%$ ). The phylogarm were depicted by NJ method, p-distance substitution model and bootstrap test of 500 times.

Table 3. Summarized information of ten top models which were evaluated by QMEAN, PROSSES, NQ-Flipper and Ramachandran online tools. The LOMET-3 model with the highest scores was selected as a model of beta-barrel domain.

\begin{tabular}{|c|c|c|c|c|c|c|}
\hline Model & TOTAL QMEAN-SCORE & $\begin{array}{c}\text { PROSSES } \\
\text { quality }\end{array}$ & $\begin{array}{c}\text { NQ-Flipper } \\
(\%)\end{array}$ & $\begin{array}{c}\text { Residues in favored } \\
\text { region }(\%)\end{array}$ & $\begin{array}{c}\text { Residues in allowed } \\
\text { region }(\%)\end{array}$ & $\begin{array}{l}\text { Residues in outlier } \\
\text { region }(\%)\end{array}$ \\
\hline LOMETS-3 & 0.392 (Z-score: -3.77) & 4.5 & $15 \%$ & $94.7 \%$ & $4.7 \%$ & $0.6 \%$ \\
\hline LOMETS-4 & 0.382 (Z-score: -3.87) & 3.5 & $20 \%$ & $92.4 \%$ & $4.7 \%$ & $2.9 \%$ \\
\hline LOMETS-7 & 0.358 (Z-score: -4.12) & 3.5 & $50 \%$ & $91.8 \%$ & $5.9 \%$ & $2.4 \%$ \\
\hline LOMETS-2 & 0.357 (Z-score: -4.13) & 4.5 & $30 \%$ & $94.7 \%$ & $2.9 \%$ & $2.4 \%$ \\
\hline LOMETS-9 & 0.354 (Z-score: -4.16$)$ & 4.5 & $40 \%$ & $93.5 \%$ & $4.7 \%$ & $1.8 \%$ \\
\hline I-TASSER-5 & 0.324 (Z-score: -4.46) & 2.5 & $5 \%$ & $80.6 \%$ & $15.9 \%$ & $3.5 \%$ \\
\hline PSIPRED-1 & 0.324 (Z-score: -4.46) & 3.5 & $25 \%$ & $94.7 \%$ & $4.1 \%$ & $1.2 \%$ \\
\hline I-TASSER-4 & 0.317 (Z-score: -4.54) & 3.5 & $15 \%$ & $72.4 \%$ & $24.1 \%$ & $3.5 \%$ \\
\hline LOMETS-5 & 0.308 (Z-score: -4.62) & 3.5 & $30 \%$ & $95.3 \%$ & $3.5 \%$ & $1.2 \%$ \\
\hline PSIPRED-2 & 0.307 (Z-score: -4.64) & 3.5 & $30 \%$ & $91.8 \%$ & $5.9 \%$ & $2.4 \%$ \\
\hline
\end{tabular}



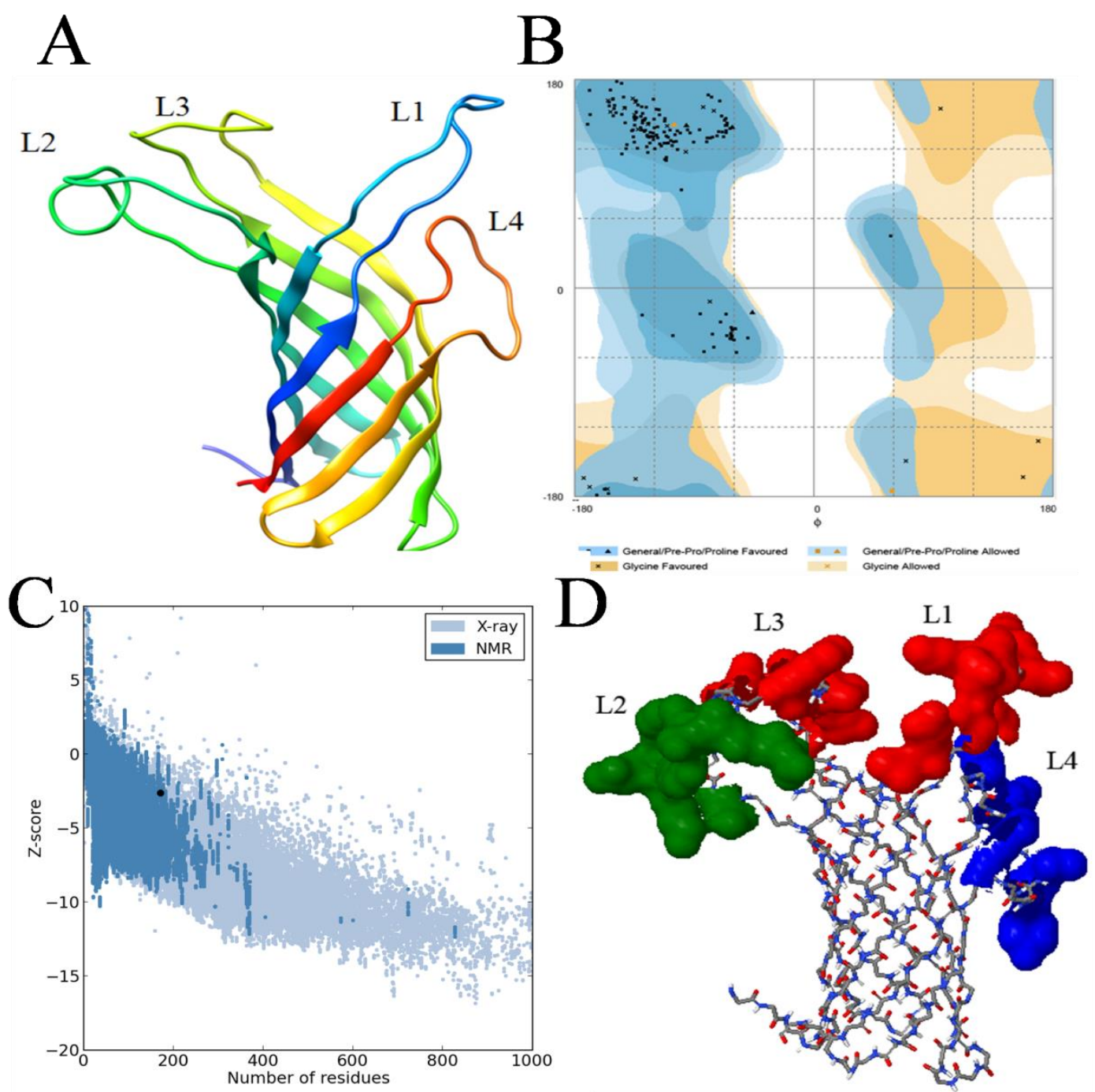

Fig. 3. (A) The refined model of the beta-barrel domain of AbOmpA protein (according to NCBI protein accession number AKF11891, beta-barrel domain encompasses residues Gly23 to Lys194). The refined model has 8 transmembrane beta strands, 4 extracellular large loops (L1, L2, L3, and L4) and short priplasmic turns (B) The Ramachandran plot of the refine model. (C) Validation of the refined model was done by PorSA web server with -2.66 Z-score. (D) Protrusion analysis showed three major exposed volumes as 1st largest protrusion (red volume located in L1 and L3), 2nd largest protrusion (green volume located in L2) and 3rd largest protrusion (blue volume located in L4).

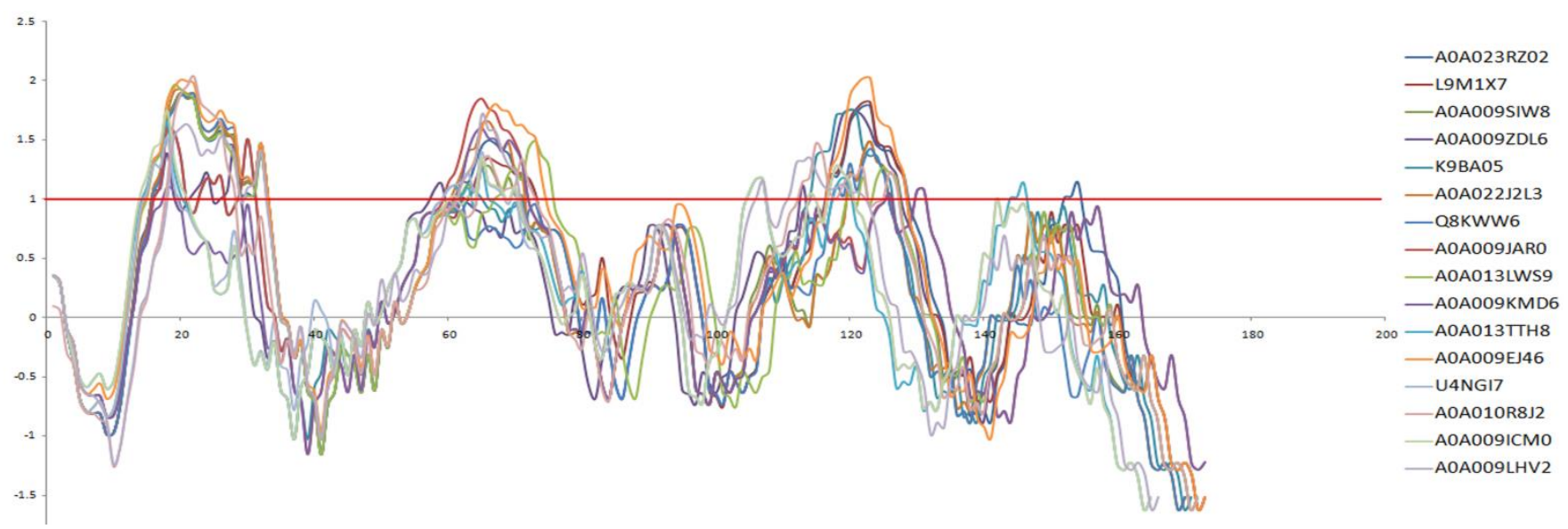

Fig. 4. Prediction of linear B cell epitopes in 16 non-redundant beta-barrel sequence patterns (redundancy cut-off was $98 \%$ ). This graph (with window size 10) shows the four highest peaks that located upon the threshold line (red line). Analysis showed these peaks exactly correspond to four extracellular loops L1, L2, L3 and L4, respectively (from left to right). Based on the sequence diversity of the extracellular loops, the epitope scores rise or fall in the graph. 
Table 4. The summarized prediction of the conformational epitopes by five independent online tools (probably cut-off $\geq 70 \%$ ). These tools predicted four regions based on residue position number of AbOmpA in the full length protein. In every row of the table, the ranges of the amino acid residues overlap each other. Sixth column shows the regions of four extracellular loops (L1, L2, L3 and L4).

\begin{tabular}{|c|c|c|c|c|c|}
\hline BEpro & EPCES & EPSVR & DiscoToPE & Ellipro & $\begin{array}{c}\text { Loop amino acid } \\
\text { positions in beta-barrel }\end{array}$ \\
\hline $\mathbf{3 9 - 5 9}$ & $42-54$ & $38-58$ & $36-59$ & $40-55$ & L1: $37-57$ \\
\hline $\mathbf{8 3 - 1 0 1}$ & $89-97$ & $79-104$ & $81-103$ & $86-99$ & L2: $85-103$ \\
\hline $\mathbf{1 3 1 - 1 4 9}$ & $133-148$ & $129-148$ & $130-151$ & $134-146$ & L3: $132-146$ \\
\hline $\mathbf{1 7 5 - 1 8 3}$ & $176-183$ & $174-183$ & $173-184$ & $177-181$ & L4: $172-186$ \\
\hline
\end{tabular}

\section{A) MHC- I binding Sites}

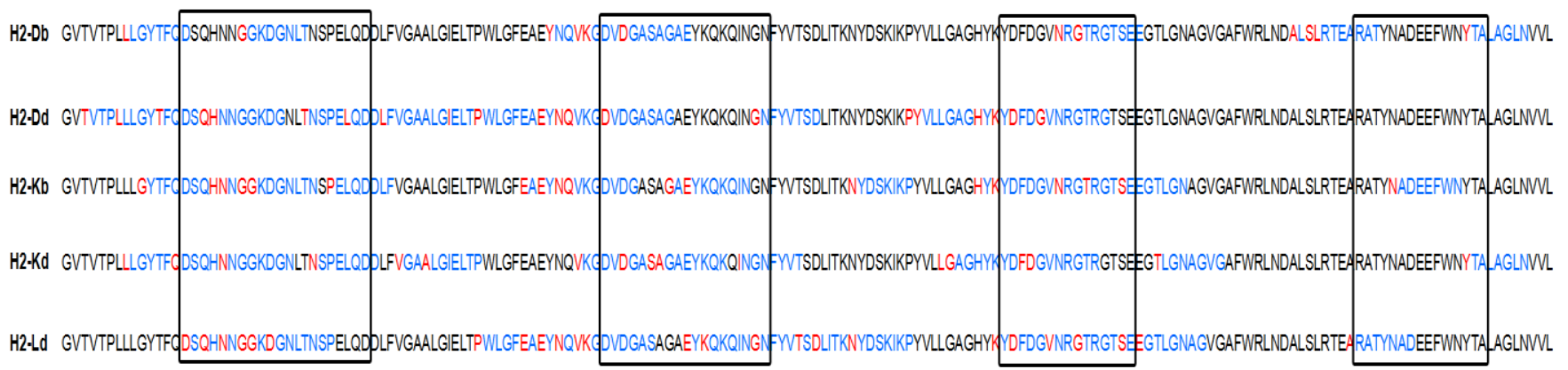

\section{B) MHC- II binding sites}

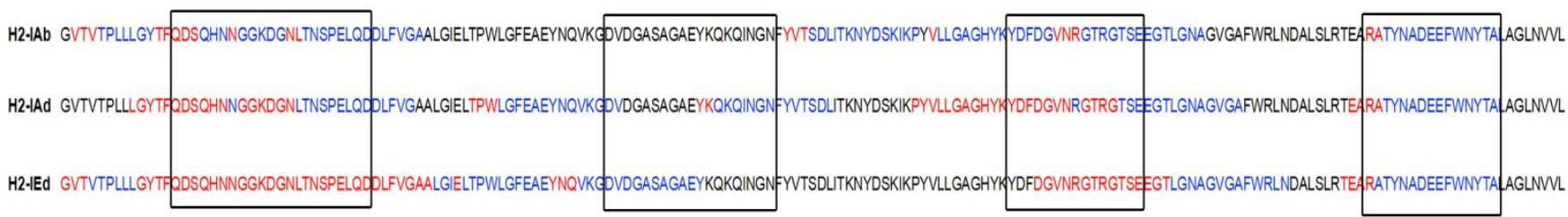

Fig. 5. Prediction of MHC-I (A) and MHC-II (B) binding sites of the beta-barrel domain based on BALB/c and C57BL/6 mice MHC alleles. The red amino acids are the start position of MHC-binding sites. Data show that MHC-I ( 8 mer, probably cut-off $\geq 90 \%)$ and MHC-II ( $15 \mathrm{mer}$, probably cut-off $\geq 90 \%)$ binding sites are significantly located on four extracellular loops of the beta-barrel domain. The rectangles represent boundaries of the extracellular L1, 2 , 3 , and 4 , respectively (from left to right).

\section{DISCUSSION}

Multi-drug resistance of $A$. baumannii is a worldwide problem $[1,29]$. The easy acquisition of resistance to antimicrobial agents by this organism leads to the failure of the therapeutic regiments[30]. Therefore, it is important to develop new approaches in order to prevent or treat the infections caused by the MDR strains. In this regard, immunological strategies such as active and passive immunization approaches could be considered as new vital options. Several studies have evaluated various vaccine candidates against $A$. baumannii infection[31]. Recently, AbOmpA has been considered as a potent vaccine candidate for protection against A.baumannii infections in diabetic mice models [32]. The results of our study showed that outer membrane protein $\mathrm{A}$ is widespread among the pathogenic members of Enterobacteriaceae and non-Enterobacteriaceae families such as A. baumannii. Although OmpA is highly conserved, the amino acid differences occur in the extracellular loops. It would be tempting to speculate that these changes may contribute to the invasiveness of the clinical isolates. Multiple sequence alignments of OmpA proteins revealed that ompA of Enterobacteriaceae family were more conserved (especially ompA of E.coli) in comparison with AbOmpA. It appears that AbOmpA plays important pathogenic roles in the clinical isolates of A. baumannii and selective immune pressures make the bacteria to change the amino acid compositions of their extracellular loops; however in case of Enterobacteriaceae, there are many other important virulence factors and such selective pressures on OmpA protein may not exist. The prevalence of type- 1 and type- 2 in silico AbOmpA sequences were 49.7\% (333 from 670) and $14.1 \%$ (95 from 670), respectively. Moreover, the frequencies of experimental data showed that $64 \%$ of the MDR isolates had type-1 (14 from 21) and $33 \%$ had type- 2 (7 from 21 ) sequences. Therefore, the high prevalence of AbOmpA type-1 in the clinical isolates of $A$. baumannii may be due to its requirement for the bacterium to play its successful pathogenic roles.

Our In silico analyses of AbOmpA type-1 showed this protein forms two independent structural domains, namely the $\mathrm{N}$ terminal domain which forms an 8 strand beta barrel channel located in the outer membrane of the bacterium with four loops 
exposed to the extracellular spaces and the C-terminal domain which forms a highly soluble and stable globular domain. The latter domain has been shown to interact with the penta-peptide portion of the peptidoglycan layer in periplasmic space [33]. Moreover, a flexible linker, consisted of a 27-residue prolinerich hinge region connects the two independent domains. Homology modeling, structural alignments and phylogenic trees showed that the beta-barrel domain of $A$. baumannii resembles to KpOmpA and has larger loops in comparison with EcOmpA (data not shown). It seems that the extracellular loops are functional regions of AbOmpA that could be associated with adherence and invasion of the eukaryotic cells, biofilm formation, immune stimulation and serum resistance. Furthermore, the amino acids variations in the extracellular loops could have influence on the invasiveness of the bacterium that should be studied among the clinical isolates in the future. Geometry analysis showed that the extracellular L1, L3, L2 and L4 were in turn highly exposed as protrusion regions in the beta-barrel domain of AbOmpA. This information coincided with the selective immune pressure hypothesis. Multiple sequence alignments of the beta-barrel domain showed that the position of L1, L3, and L2 had more amino acid changes; however, L4 was more conserved in comparison with the other loops. Interestingly, many more MHC-I and MHC-II binding sites were detected in L1 and L3 in comparison with L2 or L4. Moreover, the extracellular loops of beta-barrel domain in linear and conformational aspects had high scores as B cell epitopes. Our analysis revealed that OmpA-like domain is widespread among other proteins of the Gram-negative bacteria (data not shown). It appears that OmpA-like domain links the outer membrane to the peptidoglycan layer and is essential for the integrity of the cell. Previous quantitative and qualitative approaches have shown that outer membrane vesicles (OMVs) production is significantly increased in the $\triangle \mathrm{AbOmpA}$ mutant compared to the wild-type bacteria [34]. This data confirms that OmpA-like domain of AbOmpA plays an important role in the integrity of the outer membrane which may give rise to a controlled shedding of OMV from the surface of the bacteria.

Taken together, the results showed that AbOmpA is a totally conserved protein while it has critical roles in pathogenesis of A. baumannii. Hypothetical model of beta-barrel domain which is folded in the bacterium's outer membrane as well as the geometric characterizations showed that the major parts of the four loops are exposed to the extracellular space and could be effectively presented to the immune system. Moreover, the epitope prediction results of $\mathrm{B}$ and $\mathrm{T}$ cells suggest that the extracellular loops of the beta-barrel domain had excellent characteristics as immunogenic epitopes which could provoke both the humoral and the cellular immunity. We envisage that the extracellular loops could be used as a platform for delivering short immunogenic epitopes of other pathogenic microorganisms as vaccine targets. Based on our results, we suggest that AbOmpA type- 1 could be considered as a promising vaccine target due to its high prevalence in the clinical isolates and its immunogenic characteristics.

\section{ACKNOWLEDGMENT}

This project was funded with support from the Pasteur Institute of Iran (Ph.D. Grant No. B-8801). We would like to acknowledge Shahryar Abdoli, Hamzeh Rahimi and Maryam Rafipour for their assistance in performing the experiments and we appreciate the editing contribution of Zahra Aliabadi.

\section{CONFLICT OF INTEREST}

The authors declare that they have no conflict of interest.

\section{REFERENCES}

1. Dijkshoorn L, Nemec A, Seifert H. An increasing threat in hospitals: multidrug-resistant Acinetobacter baumannii. Nat Rev Microbiol. 2007;5(12):939-51. doi:10.1038/nrmicro1789.

2. Mortensen BL, Skaar EP. Host-microbe interactions that shape the pathogenesis of Acinetobacter baumannii infection. Cellular microbiology. 2012;14(9):1336-44.

3. Choi CH, Lee JS, Lee YC, Park TI, Lee JC. Acinetobacter baumannil invades epithelial cells and outer membrane protein A mediates interactions with epithelial cells. BMC microbiology. 2008;8(1):216.

4. Choi CH, Lee EY, Lee YC, Park TI, Kim HJ, Hyun SH et al. Outer membrane protein 38 of Acinetobacter baumannii localizes to the mitochondria and induces apoptosis of epithelial cells. Cellular microbiology. 2005;7(8):1127-38.

5. Lee JS, Choi CH, Kim JW, Lee JC. Acinetobacter baumannii outer membrane protein A induces dendritic cell death through mitochondrial targeting. The Journal of Microbiology. 2010;48(3):387-92.

6. Lee JS, Lee JC, Lee CM, Jung ID, Jeong YI, Seong EY et al. Outer membrane protein $\mathrm{A}$ of Acinetobacter baumannii induces differentiation of CD4+ T cells toward a Th1 polarizing phenotype through the activation of dendritic cells. Biochem Pharmacol. 2007;74(1):86-97. doi:10.1016/j.bcp.2007.02.012.

7. Reusch RN. Insights into the structure and assembly of Escherichia coli outer membrane protein A. FEBS Journal. 2012;279(6):894-909.

8. Smith SG, Mahon V, Lambert MA, Fagan RP. A molecular Swiss army knife: OmpA structure, function and expression. FEMS microbiology letters. 2007;273(1):1-11.

9. Renault M, Saurel O, Czaplicki J, Demange P, Gervais V, Löhr F et al. Solution state NMR structure and dynamics of KpOmpA, a 210 residue transmembrane domain possessing a high potential for immunological applications. Journal of molecular biology. 2009;385(1):117-30.

10. Moxon R, Rappuoli R. Bacterial pathogen genomics and vaccines. British medical bulletin. 2002;62(1):45-58

11. Badmasti F, Siadat SD, Bouzari S, Ajdary S, Shahcheraghi F. Molecular detection of genes related to biofilm formation in multidrug-resistant Acinetobacter baumannii isolated from clinical settings. Journal of medical microbiology. 2015:jmm. 0.000058.

12. Apweiler R, Bairoch A, Wu CH, Barker WC, Boeckmann B, Ferro S et al. UniProt: the universal protein knowledgebase. Nucleic acids research. 2004;32(suppl 1):D115-D9.

13. Thompson JD, Gibson TJ, Plewniak F, Jeanmougin F, Higgins DG. The CLUSTAL_X windows interface: flexible strategies for multiple sequence alignment aided by quality analysis tools. Nucleic acids research. 1997;25(24):4876-82.

14. Tamura K, Stecher G, Peterson D, Filipski A, Kumar S. MEGA6: molecular evolutionary genetics analysis version 6.0. Molecular biology and evolution.30(12):2725-9.

15. Benkert P, Tosatto SC, Schomburg D. QMEAN: A comprehensive scoring function for model quality assessment. Proteins: Structure, Function, and Bioinformatics. 2008;71(1):261-77.

16. Berjanskii M, Liang Y, Zhou J, Tang P, Stothard P, Zhou Y et al. PROSESS: a protein structure evaluation suite and server. Nucleic acids research. 2010;38(suppl 2):W633-W40.

17. Weichenberger CX, Sippl MJ. NQ-Flipper: validation and correction of asparagine/glutamine amide rotamers in protein crystal structures. Bioinformatics. 2006;22(11):1397-8.

18. Lovell SC, Davis IW, Arendall WB, de Bakker PI, Word JM, Prisant MG et al. Structure validation by Calpha geometry: phi,psi and Cbeta deviation. Proteins. 2003;50(3):437-50. doi:10.1002/prot.10286.

19. Xu D, Zhang Y. Improving the physical realism and structural accuracy of protein models by a two-step atomic-level energy minimization. Biophysical journal. 2011;101(10):2525-34

20. Wiederstein M, Sippl MJ. ProSA-web: interactive web service for the recognition of errors in three-dimensional structures of proteins. Nucleic acids research. 2007;35(suppl 2):W407-W10.

21. La D, Esquivel-Rodríguez J, Venkatraman V, Li B, Sael L, Ueng S et al. 3D-SURFER: software for high-throughput protein surface comparison and analysis. Bioinformatics. 2009;25(21):2843-4. 
22. Larsen J, Lund O, Nielsen M. Improved method for predicting linear Bcell epitopes. Immunome Res. 2006;2(2):1-7.

23. Liang S, Liu S, Zhang $\mathrm{C}$, Zhou Y. A simple reference state makes a significant improvement in near- native selections from structurally refined docking decoys. Proteins: Structure, Function, and Bioinformatics. 2007;69(2):244-53

24. Liang S, Zheng D, Standley DM, Yao B, Zacharias M, Zhang C. EPSVR and EPMeta: prediction of antigenic epitopes using support vector regression and multiple server results. BMC bioinformatics. 2010;11(1):381.

25. Kringelum JV, Lundegaard C, Lund O, Nielsen M. Reliable B cell epitope predictions: impacts of method development and improved benchmarking. PLoS computational biology. 2012;8(12):e1002829.

26. Ponomarenko J, Bui H-H, Li W, Fusseder N, Bourne PE, Sette A et al. ElliPro: a new structure-based tool for the prediction of antibody epitopes. BMC bioinformatics. 2008;9(1):514

27. Lundegaard C, Lamberth K, Harndahl M, Buus S, Lund O, Nielsen M. NetMHC-3.0: accurate web accessible predictions of human, mouse and monkey MHC class I affinities for peptides of length 8-11. Nucleic acids research. 2008;36(suppl 2):W509-W12.

28. Wang P, Sidney J, Dow C, Mothe B, Sette A, Peters B. A systematic assessment of MHC class II peptide binding predictions and evaluation of a consensus approach. PLoS computational biology. 2008;4(4):e1000048.

29. Katsaragakis S, Markogiannakis $H$, Toutouzas KG, Drimousis $P$, Larentzakis A, Theodoraki EM et al. Acinetobacter baumannii infections in a surgical intensive care unit: predictors of multi-drug resistance. World $\mathbf{J}$ Surg. 2008;32(6):1194-202. doi:10.1007/s00268-008-9571-3.

30. Peleg AY, Seifert H, Paterson DL. Acinetobacter baumannii: emergence of a successful pathogen. Clinical microbiology reviews. 2008;21(3):53882.

31. Garcia-Quintanilla M, R Pulido M, J McConnell M. First steps towards a vaccine against Acinetobacter baumannii. Current pharmaceutical biotechnology. 2013;14(10):897-902.

32. Luo G, Lin L, Ibrahim AS, Baquir B, Pantapalangkoor P, Bonomo RA et al. Active and passive immunization protects against lethal, extreme drug resistant-Acinetobacter baumannii infection. PloS one. 2012;7(1):e29446.
33. Jin JS, Kwon S-O, Moon DC, Gurung M, Lee JH, Kim SI et al. Acinetobacter baumannii secretes cytotoxic outer membrane protein A via outer membrane vesicles. PLoS One. 2011;6(2):e17027.

34. Moon DC, Choi CH, Lee JH, Choi C-W, Kim H-Y, Park JS et al. Acinetobacter baumannii outer membrane protein a modulates the biogenesis of outer membrane vesicles. The Journal of Microbiology. 2012;50(1):155-60.

35. Benson DA, Karsch-Mizrachi I, Lipman DJ, Ostell J, Rapp BA, Wheeler DL. GenBank. Nucleic acids research. 2000;28(1):15-8.

36. Marchler-Bauer A, Lu S, Anderson JB, Chitsaz F, Derbyshire MK DeWeese-Scott $\mathrm{C}$ et al. CDD: a Conserved Domain Database for the functional annotation of proteins. Nucleic acids research. 2011;39(suppl 1):D225-D9.

37. Berman HM, Westbrook J, Feng Z, Gilliland G, Bhat T, Weissig H et al. The protein data bank. Nucleic acids research. 2000;28(1):235-42.

38. Wu S, Zhang Y. LOMETS: a local meta-threading-server for protein structure prediction. Nucleic acids research. 2007;35(10):3375-82.

39. Roy A, Kucukural A, Zhang Y. I-TASSER: a unified platform for automated protein structure and function prediction. Nature protocols. 2010;5(4):725-38.

40. McGuffin LJ, Bryson K, Jones DT. The PSIPRED protein structure prediction server. Bioinformatics. 2000;16(4):404-5.

41. Kelley LA, Sternberg MJ. Protein structure prediction on the Web: a case study using the Phyre server. Nature protocols. 2009;4(3):363-71.

42. Bates PA, Kelley LA, MacCallum RM, Sternberg MJ. Enhancement of protein modeling by human intervention in applying the automatic programs 3D- JIGSAW and 3D- PSSM. Proteins: Structure, Function, and Bioinformatics. 2001;45(S5):39-46.

43. Holm L, Kääriäinen S, Rosenström P, Schenkel A. Searching protein structure databases with DaliLite v. 3. Bioinformatics. 2008;24(23):2780-1. 44. Larsen JE, Lund O, Nielsen M. Improved method for predicting linear B-cell epitopes. Immunome research. 2006;2(1):2.

45. Sweredoski MJ, Baldi P. PEPITO: improved discontinuous B-cell epitope prediction using multiple distance thresholds and half sphere exposure. Bioinformatics. 2008;24(12):1459-60. 